\title{
Treatment of acidic sulfate-containing wastewater using revolving algae biofilm reactors: Sulfur removal performance and microbial community characterization
}

\author{
Haoyuan Zhou ${ }^{\mathrm{a}, \mathrm{b}, \mathrm{c}, 1}$, Yanqing Sheng ${ }^{\mathrm{a}, \mathrm{c}, 1}$, Xuefei Zhao ${ }^{\mathrm{d}}$, Martin Gross ${ }^{\mathrm{d}}$, Zhiyou Wen ${ }^{\mathrm{b}, \mathrm{d}, *}$ \\ ${ }^{a}$ Key Laboratory of Coastal Zone Environmental Processes, Yantai Institute of Coastal Zone Research, Chinese Academy of Sciences, Yantai 264003, China \\ ${ }^{\mathrm{b}}$ Department of Food Science and Human Nutrition, Iowa State University, Ames, IA 50011, USA \\ ${ }^{\mathrm{c}}$ University of Chinese Academy of Sciences, Beijing 100049, China \\ ${ }^{\mathrm{d}}$ Gross-Wen Technologies Inc. 2710 S. Loop Dr. Suite 2017, Ames, IA 50010, USA
}

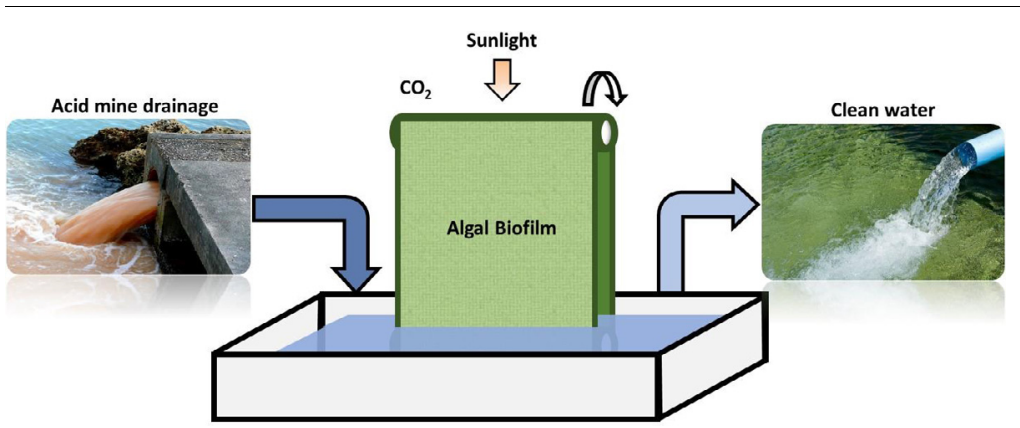

\section{A R T I C L E I N F O}

\section{Keywords:}

Acid mine drainage

Sulfate removal

Revolving algae biofilm

Microbial community

\begin{abstract}
A B S T R A C T
Industries such as mining operations are facing challenges of treating sulfur-containing wastewater such as acid mine drainage (AMD) generated in their plant. The aim of this work is to evaluate the use of a revolving algal biofilm (RAB) reactor to treat AMD with low $\mathrm{pH}(3.5-4)$ and high sulfate content $(1-4 \mathrm{~g} / \mathrm{L})$. The RAB reactors resulted in sulfate removal efficiency up to $46 \%$ and removal rate up to $0.56 \mathrm{~g} / \mathrm{L}$-day, much higher than those obtained in suspension algal culture. The high-throughput sequencing revealed that the RAB reactor contained diverse cyanobacteria, green algae, diatoms, and acid reducing bacteria that contribute the sulfate removal through various mechanisms. The RAB reactors also showed a superior performance of COD, ammonia and phosphorus removal. Collectively, the study demonstrated that RAB-based process is an effective method to remove sulfate in wastewater with small footprint and can be potentially installed in municipal or industrial wastewater treatment facilities.
\end{abstract}

\section{Introduction}

Sulfur is a contaminant commonly found in municipal and industrial effluents generated from various operations such as medication, tanning, mining, petrochemical, fermentation and food processing (Liu et al., 2012). The high sulfur-containing wastewater leads to severe environmental issues such as impoverishing aquatic flora and fauna, emissions of sulfur gases, subsidence and corrosion of foundations

\footnotetext{
* Corresponding author at: Department of Food Science and Human Nutrition, Iowa State University, Ames, IA 50011, USA

E-mail address: wenz@iastate.edu (Z. Wen).

${ }^{1} \mathrm{H}$. Zhou and Y. Sheng contributed equally to this work.
} 
(Jarvis and Younger, 2000). Sulfate as the sulfur oxidation product is the most common sulfur compound in wastewater and is usually harmless to the environment. Under anaerobic environment, however, sulfate can be converted into sulfide by sulfate reducing bacteria (SRB). Compared to sulfate, sulfide is more toxic, corrosive and odorous, and more harmful to human health. The emission of sulfide-containing offgases (e.g. $\mathrm{H}_{2} \mathrm{~S}$ ) can lead to sulfur enrichment in a waterbody causing ecological and health hazards (Li et al., 2015). Because of the significant physiological and toxicological impacts on the environment, it is important to develop effective processes to remove sulfur contaminants from wastewater.

Sulfur in wastewater can be removed through physical, chemical and biological methods. The physical methods such as electrodialysis, ion exchange and membrane filtration require high energy input. Chemical methods, such as metal precipitation, need to use excessive chemicals and replace poisoned catalysts, and thus, cause liquid contamination and reactor corrosion (Lens et al., 1998). In the bacteriabased biological sulfur removal process, sulfate is reduced into sulfide and oxidized to elemental sulfur (Xu et al., 2014). This process can emit $\mathrm{H}_{2} \mathrm{~S}$ to the atmosphere as a result of sulfate reduction. It also requires strict anaerobic conditions which can be difficult to maintain. Considering these challenges, it is essential to develop a low-cost, simple and eco-friendly methods for sulfur removal.

In recent years, microalgae-based wastewater treatment is gaining increased attention due to its environmental friendliness and potential economic benefit compared to conventional wastewater treatment processes (Gross et al., 2015). Microalgae are capable of removing various pollutants such as oxygen consumption pollutants, nitrogen, and phosphorous and metals from wastewater, the biomass produced during the treatment process can be used as feedstock for fuels, feeds, and chemicals (Kesaano and Sims, 2014). When sulfur was the targeted pollutant, an algae-based sulfur removal process is also possible because algae need to absorb sulfur in the synthesis of amino acids cysteine and methionine (Mera et al., 2016).

Compared to the other nutrients such as nitrogen and phosphorous, however, sulfur removal from wastewater has been less studied. Among limited reports of algae-based sulfur removal, researchers have studied the municipal wastewater in which the sulfur concentrations were relatively low $(\sim 300 \mathrm{mg} / \mathrm{L})$ and $\mathrm{pH}$ was neutral ( $\mathrm{Lv}$ et al., 2017, Mera et al., 2016). Contrary to the municipal wastewater, effluents from industries such as medication, tanning, mining, and petrochemical operations contain a high sulfur level ( $>2 \mathrm{~g} / \mathrm{L}$ ) (Galiana-Aleixandre et al., 2005). Among those industrial effluents, acid mine drainage (AMD) is a particular concern. In addition to high sulfur content, AMD also contains a diverse of metals (Orandi and Lewis, 2013) with an acidic $\mathrm{pH}$ ranging from 3.6-4.7 to 1.5 (Abinandan et al., 2018). Researches on AMD treatment have been mainly focusing on metal removal. For example, Orandi et al. (2012) demonstrated that an algal-microbial consortium in a rotating biological contactor was capable of removing heavy metals from AMD. Abinandan et al. (2018) reviewed the effect of microalgae and baceria interaction on the metal removal and concluded that the algae-bateria consortrium can remediate AMD. Das et al. (2009) reviewed the role of algae and fungi in the metal removal during the AMD treatment and its effects on sulfate reduction bacteria. In another study of sulfur-removal from AMD by algae-bacteria system, Sheoran and Bhandari (2005) reported that the main role of algae is to adsorb metals and nitrogen, leading to a rise of alkalinity and serving as the carbon source for sulfur reducing bacteria, which is the ultimate sulfur remover.

Our research laboratory has recently developed a revolving algal biofilm (RAB) reactor as an effective way growing microalgae (Gross et al., 2015; Gross and Wen, 2018). The RAB reactor relies on a vertically oriented materials for attached algal growth. The material travels through the water absorbing nutrients, then rotates out of the water to facilitate light exposure and $\mathrm{CO}_{2} / \mathrm{O}_{2}$ exchange. Compared to the conventional suspended growth systems, the $\mathrm{RAB}$ reactor allows for greater surface area exposure to sunlight in a much smaller footprint. The biomass productivity in the RAB reactor was 5-10 times higher than that of the open pond. Also the biomass can be harvested through scraping from the attachment material, which greatly reduced the cost compared to the centrifugation harvested processes (Gross et al., 2016). Recently, the RAB system has been successfully implemented in Metropolitan Water Reclamation District (MWRD) of Greater Chicago to remove nitrogen, phosphorus and metals from sludge thickening supernatant in MWRD facility (Kunetz et al., 2016, Zhao et al., 2018).

With prospective the success implementation of $\mathrm{RAB}$ reactor in municipal wastewater treatment, the aim of this study is to explore the utility of the RAB-based culture system for sulfur removal from AMD. Different from previous research on AMD treatment where metal removal was the focus (Orandi et al., 2012), this work focuses on a thorough evaluation of sulfur removal performance. In addition, a holistic view of the sulfur removal mechanisms was studied through identification and quantification of microbial consortium based on a high-throughput gene sequencing method.

\section{Materials and methods}

\subsection{Microalgae culture}

The microalgal seed culture was taken from a raceway pond $(1000 \mathrm{~L}$ working volume) at the Algal Production Facility at Iowa State University in Boone, IA, USA. The pond was initially inoculated with Chlorella vulgaris (UTEX \#265) and has been operated for four years. The pond culture has been maintained using Bold's Basal Medium (BBM) with half of the pond liquid being exchange with fresh medium every 7 days. Over the years, a stable algal community containing various green algae and cyanobacteria species has been established. The abundance of the mixed algal culture, particularly the original strain $C$. vulgaris, was determined based on illumina high-throughput sequencing as described in Section 2.6. This algal polyculture was used as inoculum for the bubble column and $\mathrm{RAB}$ reactors.

\subsection{Synthesis wastewater composition}

Synthetic wastewater mimicking acid mine drainage commonly found in the mining industry was used in this work. The basic recipe of the synthetic wastewater composed of (per L) $200 \mathrm{mg} \mathrm{NH} 4 \mathrm{Cl}, 50 \mathrm{mg}$ $\mathrm{KH}_{2} \mathrm{PO}_{4}, 66 \mathrm{mg} \mathrm{MgSO}_{4} \cdot 7 \mathrm{H}_{2} \mathrm{O}, 6 \mathrm{mg} \mathrm{CaCl}_{2}, 0.55 \mathrm{mg} \mathrm{FeSO}_{4} \cdot 7 \mathrm{H}_{2} \mathrm{O}$, $2.86 \mathrm{mg} \mathrm{H}_{3} \mathrm{BO}_{3}, 1.84 \mathrm{mg} \mathrm{MnCl}_{2} \cdot 4 \mathrm{H}_{2} \mathrm{O}, 0.22 \mathrm{mg} \mathrm{ZnSO} \mathrm{Z}_{4} \cdot 7 \mathrm{H}_{2} \mathrm{O}, 0.39 \mathrm{mg}$ $\mathrm{Na}_{2} \mathrm{MoO}_{4} \cdot 2 \mathrm{H}_{2} \mathrm{O}, 0.08 \mathrm{mg} \mathrm{CuSO}_{4} \cdot 5 \mathrm{H}_{2} \mathrm{O}, 0.05 \mathrm{mg} \mathrm{Co}\left(\mathrm{NO}_{3}\right)_{2} \cdot 6 \mathrm{H}_{2} \mathrm{O}$ and $375 \mathrm{mg}$ glucose. This receipt was adapted from the synthetic municipal wastewater reported previously ( $\mathrm{Lv}$ et al., 2017). The addition of glucose was used to provide COD of the acid mining drainage. To mimic the high sulfur concentration in the acid mine drainage, sodium sulfate $\left(\mathrm{Na}_{2} \mathrm{SO}_{4}\right)$ was added to the receipt at a concentration of $1 \mathrm{~g} / \mathrm{L}, 2 \mathrm{~g} / \mathrm{L}$ and $4 \mathrm{~g} / \mathrm{L}$ sulfate, respectively. The $\mathrm{pH}$ of the wastewater was 3.5-4.0 adjusted by hydrochloric acid.

\subsection{Bubble column cultures}

Sulfur removal by microalgae was evaluated in suspension-based bubble column reactors in a batch culture mode. The bubble columns contained 1-L synthetic wastewater with different sulfate concentrations. To inoculate the bubble columns, the microalgae seed culture (with an inoculum ratio of $1: 10, \mathrm{v} / \mathrm{v}$ ) was first settled for $1-2 \mathrm{~h}$, the settled slurry was then washed with DI water before being inoculated into the reactors. The bubble columns were placed at room temperature $\left(25^{\circ} \mathrm{C}\right)$ and aerated at a flow rate of $0.5 \mathrm{~L} / \mathrm{min}$ throughout the culture. Fluorescent lights were used to provide 24-hr lighting at an intensity of $130 \mu \mathrm{mol} \mathrm{cm} \mathrm{cm}^{-2} \mathrm{~s}^{-1}$. During the culture, cell density was determined based on optical density at $680 \mathrm{~nm}\left(\mathrm{OD}_{680}\right)$. 


\section{4. $R A B$ cultures}

Lab-scale RAB reactors were used to treat sulfate-containing wastewater in a continuous operation mode (HRT $=3$-day) under $24-\mathrm{hr}$ lighting $\left(130 \mu \mathrm{mol} \mathrm{cm}^{-2} \mathrm{~s}^{-1}\right)$. The details of the RAB reactor design and operation have been reported previously (Gross et al., 2015). In brief, the RAB reactor contained a liquid reservoir $(1.5 \mathrm{~L}$ working volume) and a rotating belt with a surface area of $0.13 \mathrm{~m}^{2}$ for algal attached growth. The belt rotated at $1.2 \mathrm{rpm}$ with a linear velocity of $4 \mathrm{~cm} / \mathrm{s}$. The RAB reactors were started by inoculating the algal seed culture into the liquid reservoir and rotating the RAB belt. The RAB was run for three weeks during which suspended algae gradually attached to the belt surface to establish a stable algae biofilm. During this stage, the reservoir was supplemented with BBM as necessary to compensate for water evaporative loss.

After the three-week incubation period, the RAB reactor was operated for one additional week in a continuous mode by feeding $500-\mathrm{mL}$ $\mathrm{BBM}$ and discharging spend medium daily. Then, the RAB reactors were switched to being fed with sulfate-containing wastewater. On a daily basis, the liquid reservoir was fed with $500 \mathrm{~mL}$ synthetic wastewater containing 1, 2 and $4 \mathrm{~g} / \mathrm{L}$ sulfate, respectively; with the same amount liquid being discharged. This daily feeding and discharging operation were maintained for 21 days, during which the RAB reactors were regarded as a continuous operation with a hydraulic retention time (HRT) of 3-days. To keep the biomass healthy, the biofilm in the RAB belt was harvested every 7 days through scraping with a plastic blade. The harvested biomass is a paste-like material with a moisture content of $85-95 \%(w / w)$. After harvesting, the residual colonies remaining on the belts served as inoculum for the next cycle of growth. The RAB reactors were evaluated by its removal of various nutrient parameters (sulfate, phosphorus, ammonia and COD) as follows,

Nutrient removal rate $(R, \mathrm{mg} / \mathrm{L} /$ day $)$ representing mass of the nutrients removed per unit of reactor volume per day, i.e.,

$R=F\left(C_{\text {in }}-C_{\text {out }}\right) / V=\left(C_{\text {in }}-C_{\text {out }}\right) / H R T$

where $F$ is the volumetric flow rate $(500 \mathrm{~mL} /$ day), $V$ is the RAB liquid reservoir working volume $(1.5 \mathrm{~L}), C_{i n}$ and $C_{\text {out }}$ are the nutrient concentrations in the RAB reservoir influent and effluent, respectively, HRT is the hydraulic retention time of the liquid reservoir.

Nutrient removal efficiency ( $E$, \%) representing percentage of nutrients in the influent being removed, i.e.,

$E=\left(\left(C_{i n}-C_{\text {out }}\right) / C_{\text {in }}\right) \times 100 \%$

Nutrient removal capacity based on belt surface $\left(C_{S}, \mathrm{mg} / \mathrm{m}^{2}\right.$ belt surface/day) representing mass of nutrients removed per unit of belt surface per day, i.e.,

$C_{S}=F\left(C_{\text {in }}-C_{\text {out }}\right) / S$

where $S$ is the belt surface of the RAB reactor $\left(0.13 \mathrm{~m}^{2}\right)$.

\subsection{Chemical analyses}

Sulfate concentration was measured based on Ion Chromatograph fusing APHA method 4500 (Arnold and Lenore, 1992). To measure total phosphorus (TP), water samples were digested with sulfuric acid and measured using the modified ascorbic acid method (Murphy and Riley, 1986). COD concentration was analyzed based on APHA method 5220D (Arnold and Lenore, 1992). Ammonium concentration was analyzed using the salicylate method, Hach Method 10023. To determine sulfur content of biomass of the RAB reactors, the samples were digested with nitric acid using Multiwave Go microwave (Anton Paar, Austria), and measured using the ICP-MS (Thermo Scientific, iCAP 7000 Series, USA) (Heilmann et al., 2004).

\subsection{Microbial diversity determination}

\subsubsection{DNA extraction, $P C R$ and high-throughput sequencing}

Illumina high-throughput sequencing was used to characterize microbial community in the RAB reactors. The total genomic DNA of the freeze-dried biomass samples was extracted based on the protocols described previously (Sambrook and Russel, 2001). The concentration and purity of the extracted DNA was determined based on electrophoresis using $1 \%$ agarose gels. The V4 and V5 regions of 16S rRNA gene for bacterial diversity were amplified with the primer $515 \mathrm{~F}$ ( 5'-GTGCCAGCMGCCGCGGTAA-3') and 907R (5'-CCGTCAATTCCTTTG AGTTT-3'), respectively. The V4 region of 18S rRNA gene for Eukaryota was amplified with primer 528F ( $5^{\prime}$-GCGGTAATTCCAGCTCCAA-3') and 706R (5'-AATCCRAGAATTTCACCTCT-3'). All the tags were barcoded at both ends to distinguish samples. PCR reactions were conducted in triplicate $30 \mu \mathrm{L}$ mixture composed of $15 \mu \mathrm{L} 2 \times$ Phusion Master Mix, $3 \mu \mathrm{L}$ of each primer $(6 \mu \mathrm{M}), 10 \mu \mathrm{L}$ template DNA $(1 \mathrm{ng} / \mu \mathrm{L})$ and $2 \mu \mathrm{L}$ $\mathrm{H}_{2} \mathrm{O}$. The PCR products were then purified with GeneJET ${ }^{\mathrm{TM}}$ Gel Extraction kit (Thermo Scientific, USA) and visualized on 1\% agarose gel. Sequencing libraries were sequenced on an Ion S5TM XL platform and single-end reads of $450 \mathrm{bp}$ for $16 \mathrm{~S}$ rRNA and $250 \mathrm{bp}$ for 18S rRNA, and constructed using Ion Plus Fragment Library kit 48 rxns (Thermo Scientific, USA) and quantified using the Qubit@ 2.0 Fluorometer (Thermo Scientific, USA).

\subsubsection{Analysis of microbial community diversity and richness}

Single-end reads were assigned to samples based on their unique barcode and truncated by cutting off the barcode and primer sequence using Cutadapt software (Martin, 2011). The chimera sequences were detected based on the GOLD database (Reddy et al., 2014) using UCHIME algorithm (Edgar et al., 2011) and removed to obtain the Effective Tags for subsequent analysis (Haas et al., 2011). Sequences analysis were performed by UPARSE software (Uparse v7.0.1001) (Edgar, 2013) and the same Operational Taxonomic Units (OTUs) were defined at a sequence similarity level of $97 \%$. For each OTU, the RDP classifier (Version 2.2) algorithm was used against the Silva Database (Quast et al., 2012) to annotate taxonomic information. OTUs abundance were normalized based on a standard sequence number relative to the sample with the least sequences. The output normalized data was used to perform Alpha diversity analysis. The ACE and Chao indices were used to characterize the community richness. Shannon index was used to determine the community diversity. All this indices were calculated with QIIME (Version1.7.0) (Caporaso et al., 2010) and displayed with R software (Version 2.15.3).

\section{Results and discussion}

\subsection{Sulfate removal in bubble column reactors}

The sulfur removal performance by the batch culture of microalgae in the bubble column reactors is illustrated in Fig. 1. Here, the wastewater contained $1 \mathrm{~g} / \mathrm{L}, 2 \mathrm{~g} / \mathrm{L}$ and $4 \mathrm{~g} / \mathrm{L}$ sulfate, respectively. The algae culture maintained in BBM (containing $36 \mathrm{mg} / \mathrm{L}$ sulfate) was used as control. As shown in Fig. 1A, the cell growth decreased when additional sulfate was added, indicating a sulfur inhibition to algal growth. Fig. 1B shows that the sulfate concentration reduced initially and then levelled off through the rest of culture, indicating the initial consumption of the sulfate is sufficient for the cell growth of the entire culture period. The sulfate removal efficiency was $20-25 \%$ among the three cultures (Fig. 1C), while the sulfate removal rate increased from 0.04 to $0.15 \mathrm{~g} /$ L-day with the initial sulfate concentration from 1 to $4 \mathrm{~g} / \mathrm{L}$ (Fig. 1D). Collectively, results in bubble column batch culture experiment demonstrated an inhibitory effect on cell growth by high sulfate concentration. In addition, the elevated ionic strength and acidic $\mathrm{pH}$ (3.5-4.0) caused by high sulfate concentration may also contribute the growth inhibition because algal growth commonly prefers neutral or 

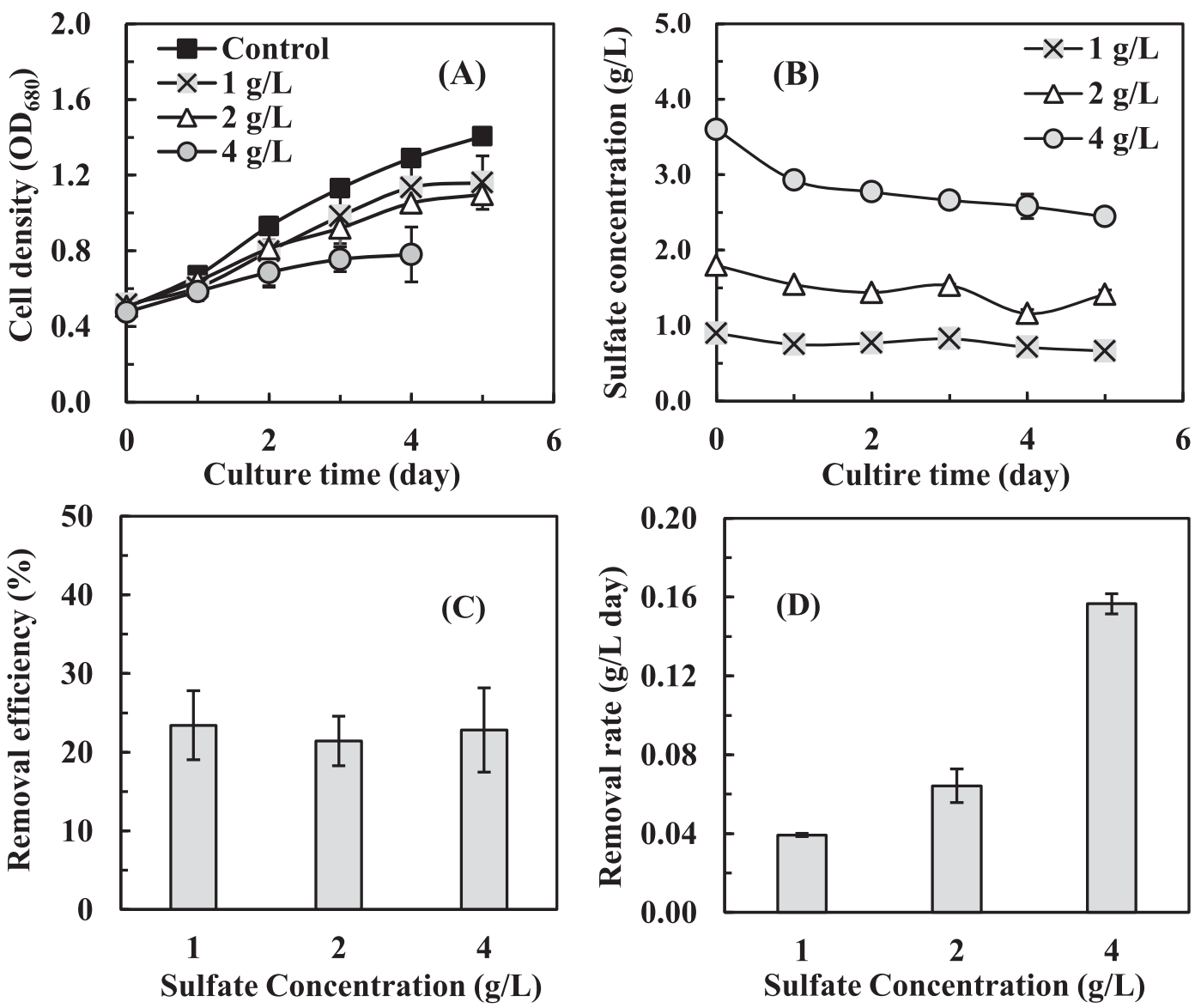

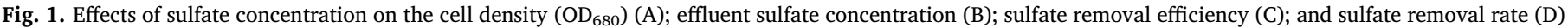

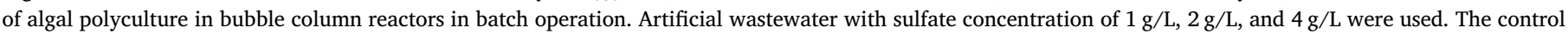

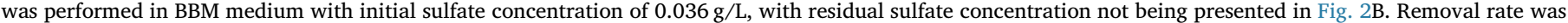
calculated by dividing the sulfate concentration reduction by the culture time.

weakly alkaline pH environment (Baldev et al., 2018).

\subsection{Sulfate removal in $R A B$ reactors}

The performance of sulfate removal in RAB reactors was evaluated by feeding the reactors with wastewater containing $1 \mathrm{~g} / \mathrm{L}, 2 \mathrm{~g} / \mathrm{L}$ and $4 \mathrm{~g} / \mathrm{L}$ sulfate, respectively. As shown in Fig. 2A, the effluent sulfate concentrations of the RAB reactors remained low values for the first 7 days when BBM (containing $0.036 \mathrm{~g} / \mathrm{L}$ sulfate) was used as influent and a stable biofilm was established. At day 7 when BBM was switched to acidic high sulfate-containing wastewater, the effluent sulfate concentrations abruptly increased. The effluent sulfur concentration fluctuated thereafter and became stable after being operated for two weeks. The steady state was reached at this stage, during which the effluent sulfate concentration was used to evaluate the sulfate removal performance. Fig. $2 \mathrm{~B}$ shows the $\mathrm{pH}$ change during the 28 days operation of the $\mathrm{RAB}$ reactors. The medium $\mathrm{pH}$ was maintained around 7.0 during the initial BBM-feeding stage. Starting from day 7 when acidic high-sulfate influents were fed to the $\mathrm{RAB}$ reactors, the $\mathrm{pH}$ gradually decreased to 4.4-4.6 at day 20, and then leveled off at this acidic $\mathrm{pH}$ level for the rest of culture, another indication of the steady state being reached.

The sulfur content in the biomass harvested at different stages of the continuous operation of the RAB reactors is illustrated in Fig. 2C. Here, we define the harvesting of biomass immediately before the sulfatecontaining influent was fed to the RAB as the initial-harvest (Fig. 2A). Fig. 2C shows that the initial-harvested biomass had lower sulfur content than the rest of the biomass due to the low sulfate concentration in the feeding medium (BBM) during this stage. When the feeding influents were switched to high sulfate-containing wastewater, the biomass sulfur content increased significantly. The increase of the biomass sulfur content was probably (partially) due to the physical adoption by the EPS in the algal biofilm (Kesaano and Sims, 2014). Fig. 2C also shows that higher sulfate concentrations resulted in more sulfate accumulation in the biomass. The biomass sulfur contents at $1 \mathrm{~g} /$ $\mathrm{L}$ and $2 \mathrm{~g} / \mathrm{L}$ sulfate feeding were relatively stable among three consecutive harvests. At $4 \mathrm{~g} / \mathrm{L}$ sulfate feeding, however, the sulfur content decreased with the harvesting passages, which was probably due to the inhibition of the algal growth at this high sulfate level leading to reduced biomass growth and EPS.

The sulfur removal performance of the RAB reactors were further evaluated through sulfate removal efficiency, removal rate and removal capacity (Eqs. (1)-(3). As shown in Fig. 3A, the sulfate removal efficiency under three influent sulfate concentrations were relatively stable, ranging from 35 to $45 \%$, which were higher than those in bubble column cultures (Fig. 1C). Both the sulfate removal rate (Fig. 3B) and removal capacity (Fig. 3C) increased with increasing sulfate concentration. Compared to the bubble column reactors, the RAB reactor resulted in a higher sulfate removal rate under each sulfate influent concentration level (Fig. 1C).

It has been reported that sulfate with over $300 \mathrm{mg} / \mathrm{L}$ was toxic to Chlamydomonas moewusii in BBM (Mera et al., 2016). While the growth of Chlorococcum sp. was not negatively affected when the alga was growing in synthetic wastewater with sulfate concentration ranging from 18 to $271 \mathrm{mg} / \mathrm{L}$ ( $\mathrm{Lv}$ et al., 2017). In this work, the sulfate concentration used was much higher than those reported in previous studies. At such high sulfate level, the suspended algae in bubble columns 

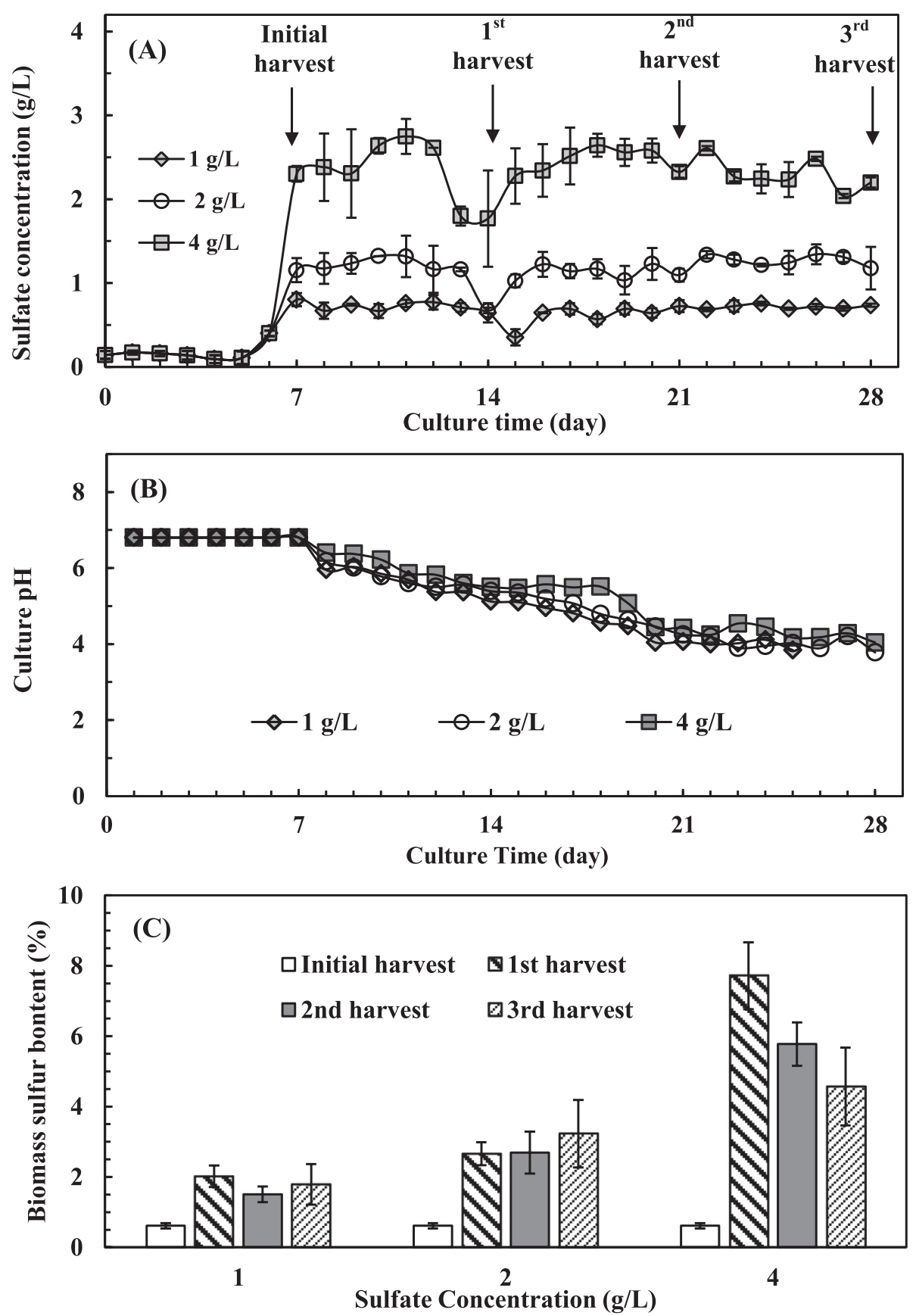

Fig. 2. Sulfate concentration in effluents (A), culture $\mathrm{pH}(\mathrm{B})$, and sulfur content of harvested biomass (C) of the RAB reactors operated at continuous mode $(\mathrm{HRT}=3$ day). The RAB reactors were fed with BBM for the first 7-days and then switched to wastewater influents containing $1 \mathrm{~g} / \mathrm{L}, 2 \mathrm{~g} / \mathrm{L}$ and $4 \mathrm{~g} / \mathrm{L}$ sulfate, respectively. The harvest sequence in Fig. 3C refers to Fig. 2A.

were inhibited (Fig. 1A), while the attached algae in $\mathrm{RAB}$ reactors demonstrated a high performance for treating acidic high sulfate-containing wastewater (Fig. 3). This may be due to the contribution of the existing algal biofilm which contains a matrix of extracellular polymeric substances (EPS) to adsorb large amount of sulfate from the liquid (Kesaano and Sims, 2014). Indeed, EPS is commonly accumulated in the biofilm system (Gross et al., 2016). In this work, the harsh environment in the RAB reactors (high sulfate with low $\mathrm{pH}$ in influent) may lead the cells to produce more EPS to resist such an adverse environment so the metabolism can be maintained (Kesaano and Sims, 2014). Additionally, the attached biofilm in the RAB reactors enable the reactor to be operated at a shorter HRT without washing-out of algal cells, which eventually increased the sulfate removal rate. In the bubble column culture, it was found that applying the same HRT to the bubble column resulted in cells washing-out (data not shown).

\subsection{Diversity and richness of bacterial and eukaryotic community in $R A B$ reactors}

The microbial community of the RAB reactors treating sulfur-containing wastewater was characterized. After removing low quality sequences and chimeras, at least 82,396 raw reads and 80,070 clean reads were obtained for each sample with a length of 372 or $373 \mathrm{bp}$. The sequence depth was adequate to measure bacterial and eukaryotic diversity since all the coverage of each sample was higher than $99 \%$ (data not shown). As shown in Table 1, OTUs of the bacterial community decreased with the culture time; while at the same culture time (day 7 or day 28), low sulfate concentration resulted in low bacterial OTUs. 

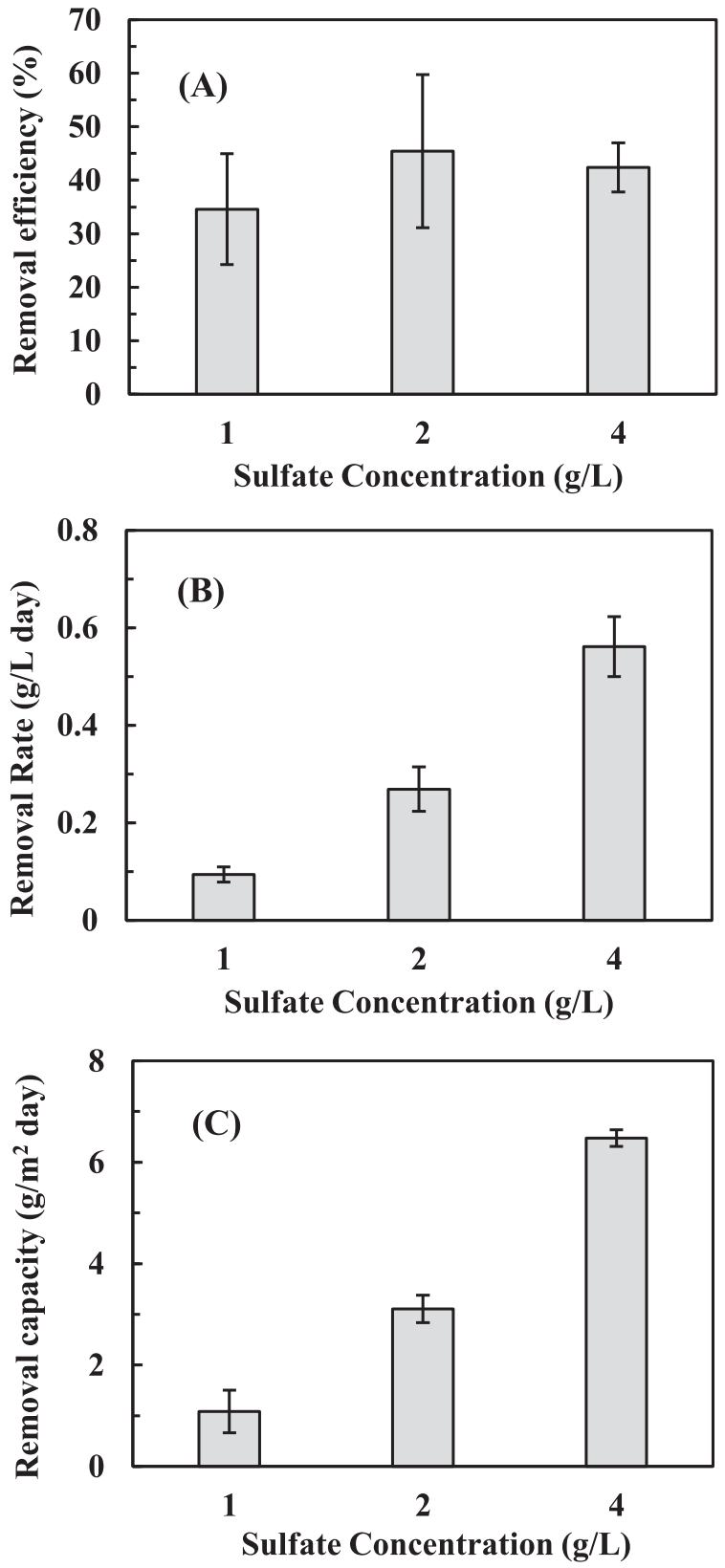

Fig. 3. Sulfate removal efficiency (A); sulfate removal rate (B); and sulfate removal capacity (C) of the RAB reactors operated at continuous mode (HRT $=3$ day) with influent sulfate concentration of $1 \mathrm{~g} / \mathrm{L}, 2 \mathrm{~g} / \mathrm{L}$ and $4 \mathrm{~g} / \mathrm{L}$, respectively.

Table 1

Bacterial community richness and diversity indices of the biomass harvested at different culture times and sulfate feeding concentrations of the RAB reactors.

\begin{tabular}{lllllll}
\hline \multicolumn{2}{l}{ Biomass samples } & Reads & OTUs & ACE & Chao & Shannon \\
\cline { 1 - 5 } Culture time & $\begin{array}{l}\text { Sulfate concentration } \\
(\mathrm{g} / \mathrm{L})\end{array}$ & & & & & \\
\hline \multirow{2}{*}{ Day 1} & $\mathrm{~N} / \mathrm{A}$ & 52,069 & 601 & 630 & 616 & 5.34 \\
Day 7 & 1 & 56,383 & 474 & 505 & 497 & 4.28 \\
& 2 & 52,372 & 550 & 586 & 584 & 5.08 \\
& 4 & 59,890 & 611 & 650 & 643 & 5.37 \\
Day 28 & 1 & 69,873 & 182 & 230 & 207 & 3.01 \\
& 2 & 68,207 & 279 & 339 & 338 & 2.61 \\
& 4 & 68,622 & 269 & 340 & 321 & 3.20 \\
\hline
\end{tabular}

Table 2

Eukaryotic community richness and diversity indices of the biomass harvested at different culture times and sulfate feeding concentrations of the RAB reactors.

\begin{tabular}{lllllll}
\hline \multicolumn{2}{l}{ Biomass samples } & Reads & OTUs & ACE & Chao & Shannon \\
\cline { 1 - 5 } Culture time & $\begin{array}{l}\text { Sulfate concentration } \\
\text { (g/L) }\end{array}$ & & & & & \\
\hline \multirow{2}{*}{ Day 1} & N/A & & & & & \\
Day 7 & 1 & 55,282 & 210 & 216 & 217 & 5.37 \\
& 2 & 65,194 & 232 & 237 & 235 & 5.14 \\
& 4 & 58,682 & 218 & 226 & 231 & 5.10 \\
Day 28 & 1 & 59,708 & 219 & 228 & 229 & 5.16 \\
& 2 & 62,557 & 174 & 183 & 181 & 4.69 \\
& 4 & 58,704 & 179 & 191 & 185 & 4.98 \\
& 48,047 & 179 & 183 & 180 & 5.07 \\
\hline
\end{tabular}

The ACE, Chao and Shannon estimators showed a similar trend, indicating reduced richness and diversity of the bacterial community with culture progressing (Table 1 ). Table 2 shows that richness and diversity indices of eukaryotic community. The OTUs decreased from the range of 218-232 at day 7 to the range of $174-179$ at day 28. The ACE, Chao and Shannon values decreased from day 7 to day 28 , indicating a reduced richness and diversity of the eukaryotic diversity with culture progressing.

The specific and common bacteria and eukaryotic OTUs were further evaluated at species level. Fig. 4A shows that the bacteria community had a total of 263 OTUs in common for the cultures in days 1 and 7 (with three sulfate concentrations), representing $28 \%$ of total sequences (940 OTUs) during this culture period. However, the common OTUs reduced to 96 (13\% of total sequences) when culture extended to day 28 (Fig. 4B). The Venn diagrams for the eukaryotic communities (Fig. 4C and D) show that the common OTUs reduced from 137 ( $48 \%$ of total sequences) to 102 (37\% of total sequences) when the culture was extended day 7 to day 28 .

Overall, the above results indicated that the diversity the RAB biomass contained more diverse bacterial species than eukaryotic species. With the culture progressing, the community of both bacterial and eukaryotic communities reduced.

\subsection{Compositions of bacterial and eukaryotic community in $R A B$ reactors}

Taxonomic classification revealed that bacteria were predominant of all classifiable $16 \mathrm{~S}$ rRNA sequences. Fig. 5A shows that at the initial sulfur feeding stage (day 1), Proteobacteria and Cyanobacteria were dominant. Proteobacteria is a bacterial phylum some of which can facilitate the bacteria adherence to form biofilm (Mhedbi-Hajri et al., 2011); Cyanobacteria was predominant in our seed algal pond. After $\mathrm{RAB}$ reactors were fed sulfur-containing influent for 7 days, Proteobacteria and Cyanobacteria still dominated the community, while Bacteroidetes population increased. The abundance of Bacteroidetes has been detected in other sulfate reduction environments such as heavy-metal contaminated soil (Sitte et al., 2010) or metal-rich landfill leachate (Schmidtova and Baldwin, 2011). At day 28, Proteobacteria was still dominant in the community. Meanwhile, the acidopilic Acidobacteria increased to a range of $7.45 \%-15.53 \%$, suggesting the acid environment provided a favorable condition for this bacteria to thrive (Lladó et al., 2016). Acidobacteria has been reported to withstand high metal content and acidic pH in other studies (Barns et al., 2007). The Cyanobacteria population still accounted as major population at day 28, but its relative abundance reduced compared to days 1 and 7 . Bacteroidetes abundance also decreased particularly at $2 \mathrm{~g} / \mathrm{L}$ and $4 \mathrm{~g} / \mathrm{L}$ sulfate.

Regarding the composition of the present genus, Fig. 5B shows that Leptolyngbya, a very thin $(<3 \mu \mathrm{m})$ filamentous cyanobacteria (Albertano et al., 2000), was most abundant at day 1 but declined 

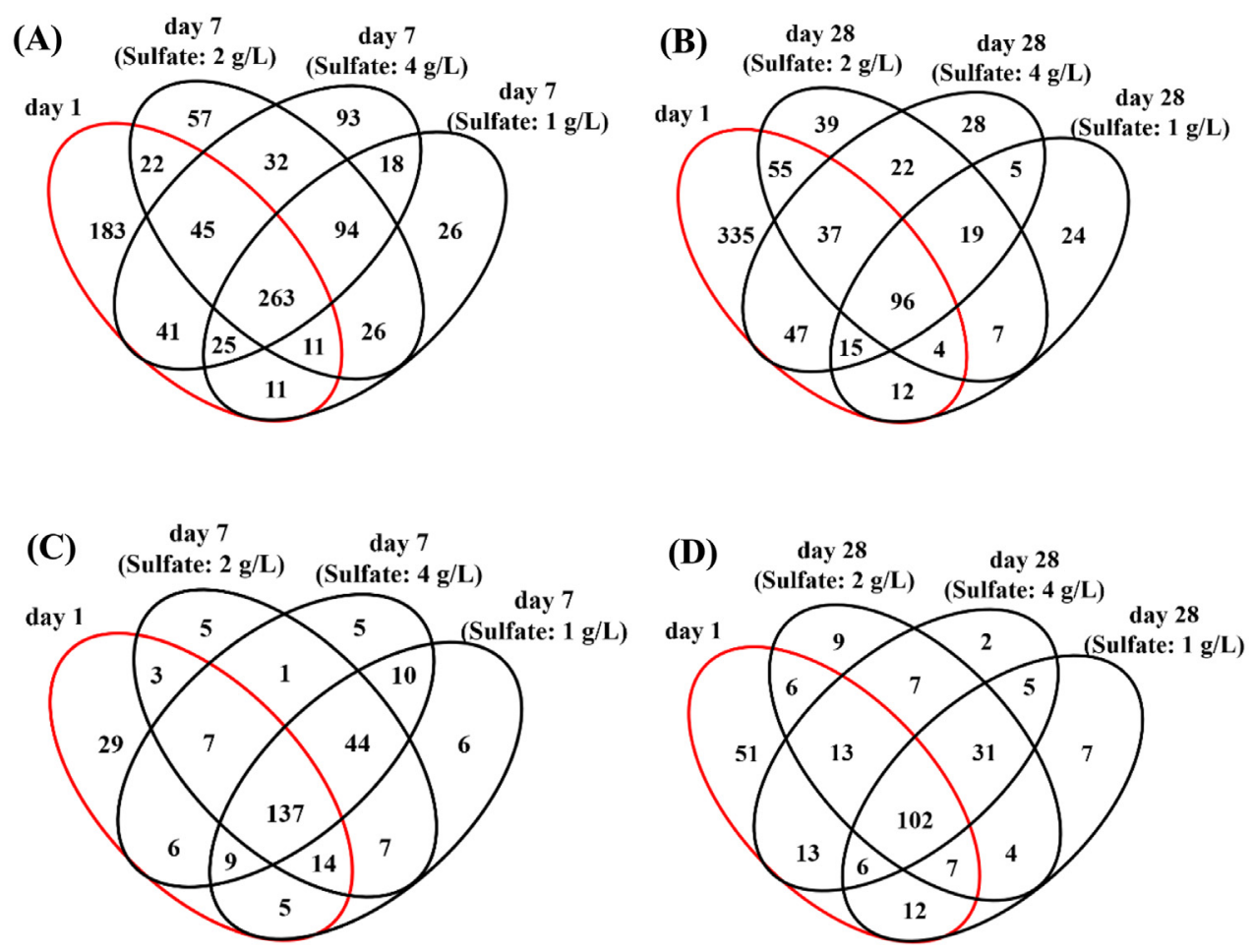

Fig. 4. Venn analysis of the bacterial and eukaryotic communities of the RAB reactors fed with influent containing different sulfate concentrations (based on OTUs at 3\% distance). (A) Bacteria species progressing from day 1 to day 7; (B) Bacteria species progressing from day 1 to day 28 ; (C) Eukaryotic species progressing from day 1 to day 7; (D) Eukaryotic species progressing from day 1 to day 28 . sharply at days 7 and 28. An unidentified genus (Chloroplast class) and Pseudanabaena (both belonging to Cyanobacteria phylum) were abundant at day 7. While at day 28, Terriglobus and Dyella, respectively belonging to Acidobacteria and Proteobacteria phylum, became predominant. Previous researches have detected Terriglobus in the oilcontaminated soil (Abed et al., 2015) and sulfate reducing environment (Green-Saxena et al., 2014).

The abundance of eukaryotic community was also presented. As shown in Fig. 6A, Apsomycote, an unidentified phylum (Eukaryota), Eustigmatophyceae, Chytridiomycota and Diatomea were dominant at day 1. At days 7 and 28, Ascomycota was more abundant; while Eustigmatophyceae and Chytridiomycota population decreased and the unidentified phylum (Eukaryota) maintained stable. The population of green alga Chlorophyta increased at day 7 but decreased at day 28 . Previous studies have reported the existence of Ascomycota phylum during litter decay (Vořŕšková and Baldrian, 2013), and the existence of the green alga Chlorophyta phylum in a variety of environments (Paul and Fenical, 1987). At day 28, Basidiomycota population increased significantly attributing to the acid environment (Baker et al., 2009).

At genus level, Fig. 6B shows that Nannochloropsis, a diatom alga, was the most abundant member at day 1, but declined at days 7 and 28 . However, Acutodesmus (belongs to Chlorophyta phylum), a microalga with resistant cell wall (Gruber-Brunhumer et al., 2015), increased its abundance with the culture progressing from day 1 to day 7 but decreased again to a relative low level at day 28 . It should be note that the alga Chlorella vulgaris, the original species inoculated for the open pond culture, was not detected in the RAB biofilm at day 1 . The results indicate a drastic community change of the algal pond culture and RAB cultures.

Collectively, the above results show a dynamic change of the bacteria, cyanobacteria, eukaryotic algae and fungi during the treatment of acidic high sulfate-containing wastewater by the RAB reactors. The culture time and influent sulfate concentration significantly affected the bacterial and eukaryotic community constituents. With time evolving, various acidophilic bacteria, cyanobacteria, eukaryotic algae co-existed in the biofilm contributing the sulfate removal. For exmaple, in the bacterial community (Fig. 5B), Hydrogenophaga is a sulfate-reducing bacteria (SRB) (Wei et al., 2010) while Rhodobacter was capable of assimilating sulfate (Cooper and Trüper, 1985). Aquimonas, Curtobacterium, Arenimonas, and Terriglobus have also been found in various acidic sulfur-containing environments (Abed et al., 2015, Liu et al., 2015). Microalgae in the RAB reactors included cyanobacteria (Cyanobacterium and Leptolyngbya) (Fig. 5B), green algae (Scenedesmus, Acutodesmus and Poterioochromonas) and diatom (Nannochloropsis and Nitzschia) (Fig. 6B). It is believed that these microalgae removed sulfur from wastewater through assimilation as a nutrient (Lv et al., 2017, Mera et al., 2016). Such a diverse of species indicates that the sulfate removal by the RAB reactor may be based on a mixed mechanism such as bacteria-based reduction and microalgae-based assimilation. The bacterial and algae consortium can adapt to the wastewater environment and form a stable symbiosis system, realizing a robust pollutant removal. Further study is needed to elucidate the synergism of algaebacteria interaction, and its implication in sulfur removal.

\subsection{Nutrients (ammonia and phosphorus) and COD removal by the RAB} reactors

The characteristics of the microbial community reported above also revealed that the RAB reactors have certain capability of the removing nutrients (ammonia, phosphorus) and COD from the influent. For example, Proteobacteria, which was dominant in the bacterial community (Fig. 5A), contain some ammonia-oxidizing bacteria (Kowalchuk et al., 1997). Several algae (Scenedesmus, Acutodesmus and Nannochloropsis) were capable of removing phosphorus (Kim et al., 2016). The bacteria Acidobacteria (such as Terriglobus), and algae such as Eustigmatophyceae (Nannochloropsis) and Chlorophyta (Acutodesmus) can also consume organic carbon and thus benefit for COD removal (Kim et al., 2016, Velu et al., 2015). A mixed algae-bacteria based biofilm was capable of removing sulfate as well as other nutrients from secondary stage municipal wastewater (Shayan et al., 2016).

In this work, therefore, the RAB reactors were further evaluated for its capability of removing COD, ammonia and phosphorus. As shown in Table 3, the RAB reactors had an excellent performance for TP removal $(\sim 100 \%)$ under different influent sulfate concentrations. For ammonia 

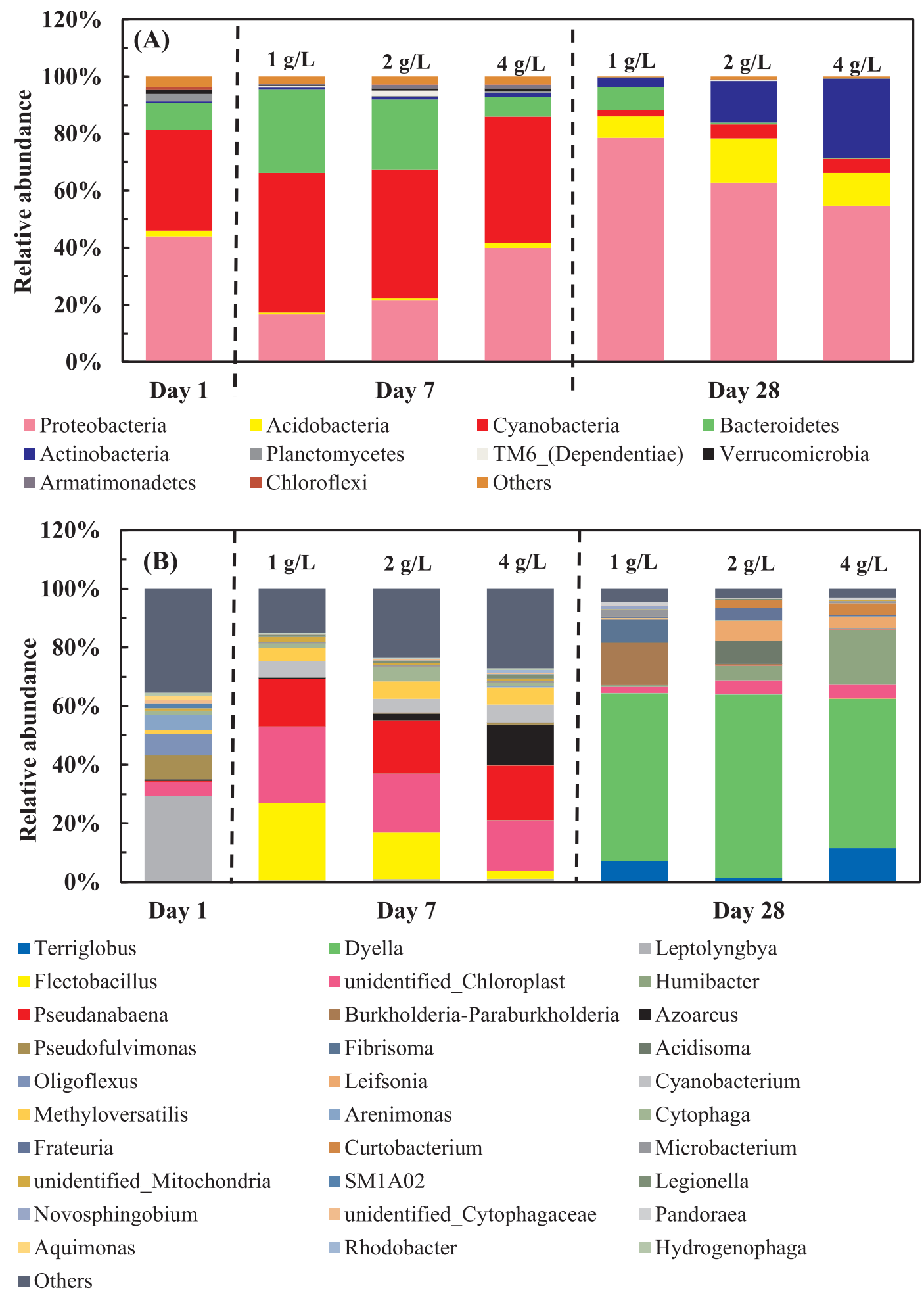

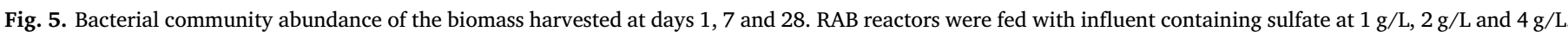
(A): phylum level, (B): genus level.

removal, the RAB reactors removed 69\% ( $1 \mathrm{~g} / \mathrm{L}$ sulfate), $68 \%(2 \mathrm{~g} / \mathrm{L}$ sulfate) and $52 \%$ ( $4 \mathrm{~g} / \mathrm{L}$ sulfate) ammonia from the influent, indicating high sulfate concentration may inhibit the ammonia removal from the influent. Comparison of TP and ammonia removal efficiency indicates that the RAB culture may be limited by phosphorus, while ammonia was supplied in excess. Table 3 also shows that the three RAB reactors had an excellent COD removal performance. For example, the influent fed to the reactors contained $400 \mathrm{mg} / \mathrm{L} \mathrm{COD}$; the effluent COD concentration was lower than $50 \mathrm{mg} / \mathrm{L}$, resulting in over $90 \%$ COD being removed. The high sulfate content in the influent did not exhibit any negative effect on the COD removal. Collectively, Table 3 indicate that influent sulfate concentration played an important role for the nutrients and COD removal efficiency, and $2 \mathrm{~g} / \mathrm{L}$ was the optimal sulfate concentration for a maximum TP, ammonia and the COD removal. The effects of sulfur concentration on the nutrients and COD removal was also reported by other researchers. For example, Lv et al. (2017) 

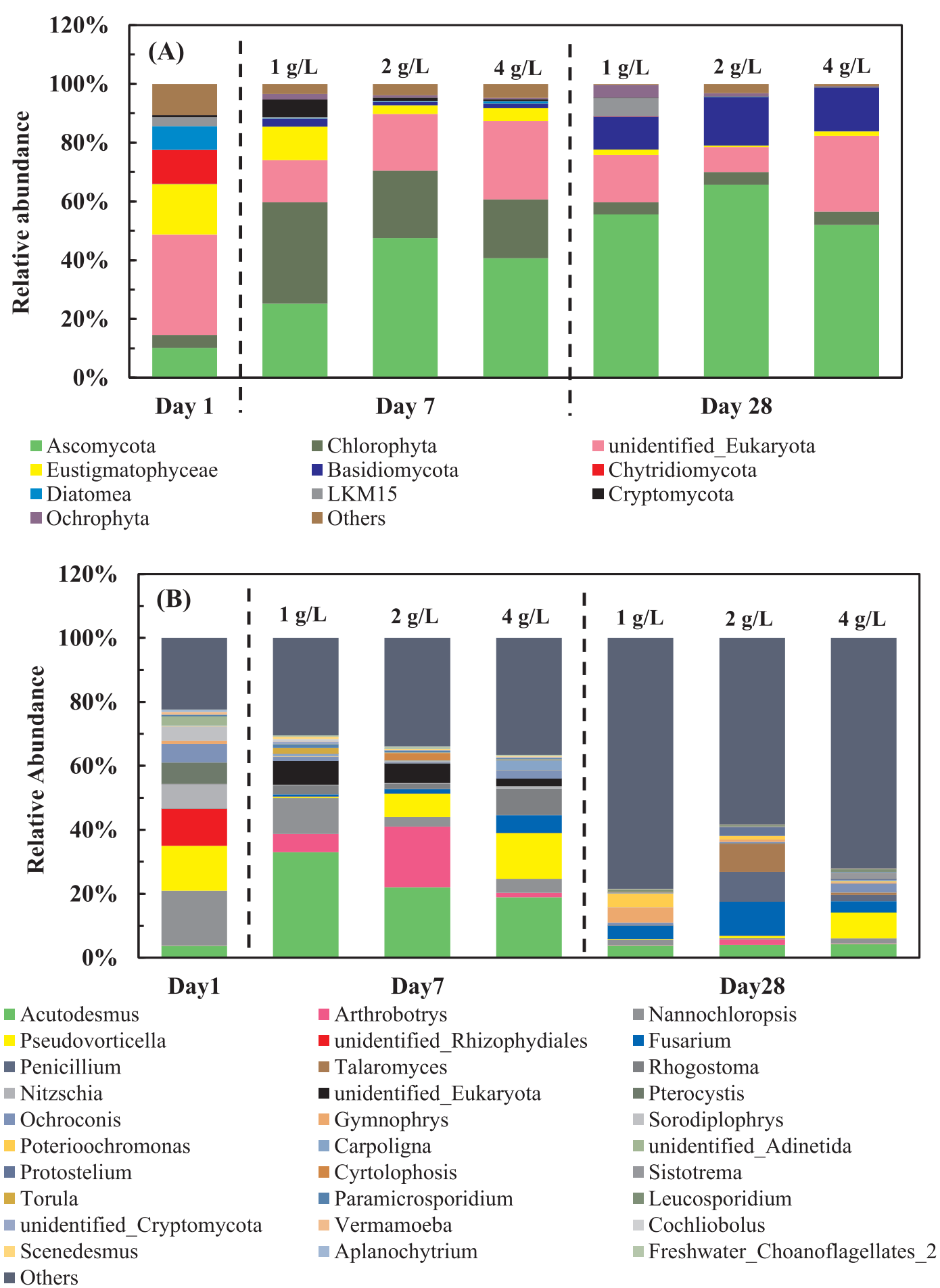

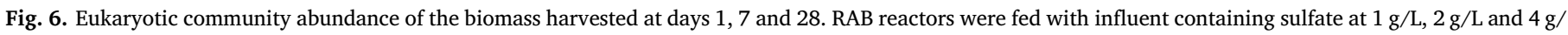
L. (A): phylum level, (B): genus level.

found that the removal efficiency of COD, ammonia and phosphorous decreased at sulfate deficient condition, while remained relatively stable when the sulfate concentration increased from $18 \mathrm{mg} / \mathrm{L}$ to $271 \mathrm{mg} / \mathrm{L}$. Our results further indicated that excessive sulfate may result inhibition on nutrient removal.

\section{Conclusion}

$\mathrm{RAB}$ reactor is an effective system for treating acidic sulfate containing wastewater. The sulfate removal efficiency was within the range of $35-46 \%$, two times higher than the bubble column reactors. The sulfate removal rate and removal capacity reached up to $0.56 \mathrm{~g} / \mathrm{L}$-day and $6.47 \mathrm{~g} / \mathrm{m}^{2}$-day, respectively. $\mathrm{RAB}$ reactors contained a diverse bacterial and algae community, which provided a superior sulfur removal performance through various mechanisms such as reduction and assimilation. In addition to the sulfate removal, the RAB reactors also achieved excellent ammonia, phosphorus and COD removal performance. Further efforts are needed to optimize the RAB operational conditions. 
Table 3

Nutrients (ammonia and total phosphorus, TP) and COD removal performance by the RAB reactors fed with influents containing different sulfate concentrations.

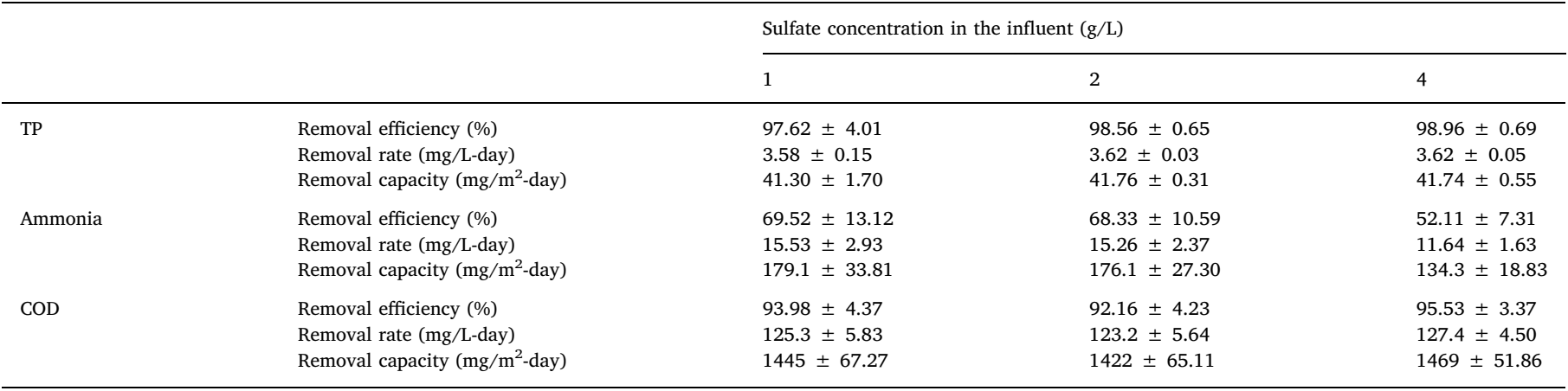

\section{Acknowledgements}

This project was funded by China Scholarship Council, Yantai Institute of Coastal Zone Research, Chinese Academy of Sciences, and Iowa State University. Additional support was provided by the National Natural Science Foundation of China (Grant No.: 41373100). The authors acknowledge Dr. Jun Chen, Shaoling Sun (Yantai Institute of Coastal Zone Research, CAS), Dr. Huichao Zhang (Yantai University, China), Max Gangestad and Show-Ling Lee (Iowa State University) for their generous assistance. Z. Wen and M. Gross have equity interests and management roles in Gross-Wen Technologies, Inc. The terms of this arrangement have been reviewed and approved by Iowa State University in accordance with its conflict of interest policies. No nonfinancial competing interests exist for any of the authors.

\section{References}

Abed, R.M., Al-Kindi, S., Al-Kharusi, S., 2015. Diversity of bacterial communities along a petroleum contamination gradient in desert soils. Microb. Ecol. 69 (1), 95-105.

Abinandan, S., Subashchandrabose, S.R., Venkateswarlu, K., Megharaj, M., 2018. Microalgae-bacteria biofilms: a sustainable synergistic approach in remediation of acid mine drainage. Appl. Micr. B. 102 (3), 1131-1144.

Albertano, P., Barsanti, L., Passarelli, V., Gualtieri, P., 2000. A complex photoreceptive structure in the cyanobacterium Leptolyngbya sp. Micron. 31 (1), 27-34.

Arnold, E., Lenore, S., 1992. Standard methods for the examination of water and wastewater. American Public Health Association, USA.

Baker, B.J., Tyson, G.W., Goosherst, L., Banfield, J.F., 2009. Insights into the diversity of eukaryotes in acid mine drainage biofilm communities. Appl. Envir. 75 (7), 2192-2199.

Baldev, E., Mubarakali, D., Saravanakumar, K., Arutselvan, C., Alharbi, N.S., Alharbi, S.A., Sivasubramanian, V., Thajuddin, N., 2018. Unveiling algal cultivation using raceway ponds for biodiesel production and its quality assessment. Renew. Energy 123, 486-489.

Barns, S.M., Cain, E.C., Sommerville, L., Kuske, C.R., 2007. Acidobacteria phylum sequences in uranium-contaminated subsurface sediments greatly expand the known diversity within the phylum. Appl. Envir. 73 (9), 3113-3116.

Caporaso, J.G., Kuczynski, J., Stombaugh, J., Bittinger, K., Bushman, F.D., Costello, E.K. Fierer, N., Pena, A.G., Goodrich, J.K., Gordon, J.I., 2010. QIIME allows analysis of high-throughput community sequencing data. Nat. Methods 7 (5), 335.

Cooper, B.P., Trüper, H.G., 1985. Sulfate activation in Rhodobacter sulfidophilus and other species of the Rhodospirillaceae. Arch. Microb. 141 (4), 384-391.

Das, B.K., Roy, A., Koschorreck, M., Mandal, S.M., Wendt-Potthoff, K., Bhattacharya, J., 2009. Occurrence and role of algae and fungi in acid mine drainage environment with special reference to metals and sulfate immobilization. Water Res. 43 (4), 883-894.

Edgar, R.C., 2013. UPARSE: highly accurate OTU sequences from microbial amplicon reads. Nat. methods 10 (10), 996.

Edgar, R.C., Haas, B.J., Clemente, J.C., Quince, C., Knight, R., 2011. UCHIME improves sensitivity and speed of chimera detection. Bioinformat. 27 (16), 2194-2200.

Galiana-Aleixandre, M., Iborra-Clar, A., Bes-Piá, B., Mendoza-Roca, J., Cuartas-Uribe, B., Iborra-Clar, M., 2005. Nanofiltration for sulfate removal and water reuse of the pickling and tanning processes in a tannery. Desalinatn. 179 (1-3), 307-313.

Green-Saxena, A., Dekas, A.E., Dalleska, N.F., Orphan, V.J., 2014. Nitrate-based niche differentiation by distinct sulfate-reducing bacteria involved in the anaerobic oxidation of methane. ISME J. 8 (1), 150.

Gross, M., Mascarenhas, V., Wen, Z., 2015. Evaluating algal growth performance and water use efficiency of pilot-scale revolving algal biofilm (RAB) culture systems. Biotechnol. Bioeng. 112 (10), 2040-2050.

Gross, M., Zhao, X., Mascarenhas, V., Wen, Z., 2016. Effects of the surface physico-chemical properties and the surface textures on the initial colonization and the attached growth in algal biofilm. Biotechnol. Biofuels. 9 (1), 38.

Gross, M.A., Wen, Z., 2018. Photobioreactor systems and methods. US Patent 9932549.

Gruber-Brunhumer, M., Jerney, J., Zohar, E., Nussbaumer, M., Hieger, C., Bochmann, G., Schagerl, M., Obbard, J., Fuchs, W., Drosg, B., 2015. Acutodesmus obliquus as a benchmark strain for evaluating methane production from microalgae: influence of different storage and pretreatment methods on biogas yield. Algal Res. 12, 230-238.

Haas, B.J., Gevers, D., Earl, A.M., Feldgarden, M., Ward, D.V., Giannoukos, G., Ciulla, D. Tabbaa, D., Highlander, S.K., Sodergren, E., 2011. Chimeric 16S rRNA sequence formation and detection in Sanger and 454-pyrosequenced PCR amplicons. Genome. Res. 21 (3), 494-504.

Heilmann, J., Boulyga, S.F., Heumann, K.G., 2004. Accurate determination of sulfur in gasoline and related fuel samples using isotope dilution ICP-MS with direct sample injection and microwave-assisted digestion. Anal. Bioanal. Chem. 380 (2), 190-197.

Jarvis, A.P., Younger, P.L., 2000. Broadening the scope of mine water environmental impact assessment: a UK perspective. Environ. Impact Assess. Rev. 20 (1), 85-96.

Kesaano, M., Sims, R.C., 2014. Algal biofilm based technology for wastewater treatment. Algal Res. 5, 231-240.

Kim, H.-C., Choi, W.J., Chae, A.N., Park, J., Kim, H.J., Song, K.G., 2016. Treating highstrength saline piggery wastewater using the heterotrophic cultivation of Acutodesmus obliquus. Bioch. Eng. J. 110, 51-58.

Kowalchuk, G.A., Stephen, J.R., De Boer, W., Prosser, J.I., Embley, T.M., Woldendorp, J.W., 1997. Analysis of ammonia-oxidizing bacteria of the beta subdivision of the class Proteobacteria in coastal sand dunes by denaturing gradient gel electrophoresis and sequencing of PCR-amplified 16S ribosomal DNA fragments. Appl. Environ. Microb. 63 (4), 1489-1497.

Kunetz, T.E., Kumar, K., Gross, M.A., Wen, Z., 2016. Evaluation of the performance of a revolving algae biofilm system for recovering nitrogen and phosphorus from municipal wastewater. Proc. Water Environ. Federation WEFTEC Conf. 14, 2988-3000.

Lens, P.N.L., Visser, A., Janssen, A.J.H., Pol, L.W.H., Lettinga, G., 1998. Biotechnological treatment of sulfate-rich wastewaters. Crit. Rev. Env. Sci. Tec. 28 (1), 41-88.

Li, L., Zhang, J., Lin, J., Liu, J., 2015. Biological technologies for the removal of sulfur containing compounds from waste streams: bioreactors and microbial characteristics. World J. Microb. Biot. 31 (10), 1501-1515.

Liu, C., Zhao, C., Wang, A., Guo, Y., Lee, D.-J., 2015. Denitrifying sulfide removal process on high-salinity wastewaters. Appl. Microbiol. Biot. 99 (15), 6463-6469.

Liu, X., Jiang, D.L., Yong, Y., 2012. Biological sulfur and nitrogen removal from wastewater. Trans. Tech. Publ. 2170-2173.

Lladó, S., Žifčáková, L., Větrovský, T., Eichlerová, I., Baldrian, P., 2016. Functional screening of abundant bacteria from acidic forest soil indicates the metabolic potential of Acidobacteria subdivision 1 for polysaccharide decomposition. Biol. Fert. S. 52 (2), 251-260.

Lv, J., Guo, J., Feng, J., Liu, Q., Xie, S., 2017. Effect of sulfate ions on growth and pollutants removal of self-flocculating microalga Chlorococcum sp. GD in synthetic municipal wastewater. Bioresour. Technol. 234, 289-296.

Martin, M., 2011. Cutadapt removes adapter sequences from high-throughput sequencing reads. EMBnet. J. 17 (1), 10-12.

Mera, R., Torres, E., Abalde, J., 2016. Effects of sodium sulfate on the freshwater microalga Chlamydomonas moewusii: implications for the optimization of algal culture media. J. Phycol. 52 (1), 75-88.

Mhedbi-Hajri, N., Jacques, M.-A., Koebnik, R., 2011. Bacterial Adhesion. Springer, pp. 71-89.

Murphy, J., Riley, J.P., 1986. Citation-Classic - a modified single solution method for the determination of phosphate in natural-waters. Cc/Agr Biol. Environ. 121616.

Orandi, S., Lewis, D.M., 2013. Synthesising acid mine drainage to maintain and exploit indigenous mining micro-algae and microbial assemblies for biotreatment investigations. Environ. Sci. Pollut. R. 20 (2), 950-956.

Orandi, S., Lewis, D., Moheimani, N., 2012. Biofilm establishment and heavy metal removal capacity of an indigenous mining algal-microbial consortium in a photo-rotating biological contactor. J. Ind. Microbiol. Biot. 39 (9), 1321-1331.

Paul, V.J., Fenical, W., 1987. Bioorganic marine chemistry. Springer 1-29.

Quast, C., Pruesse, E., Yilmaz, P., Gerken, J., Schweer, T., Yarza, P., Peplies, J., Glöckner, F.O., 2012. The SILVA ribosomal RNA gene database project: improved data processing and web-based tools. Nucl. Acid R. 41 (D1), D590-D596.

Reddy, T.B., Thomas, A.D., Stamatis, D., Bertsch, J., Isbandi, M., Jansson, J., Mallajosyula, J., Pagani, I., Lobos, E.A., Kyrpides, N.C., 2014. The Genomes OnLine 
Database (GOLD) v. 5: a metadata management system based on a four level (meta) genome project classification. Nucl. Acid R. 43(D1), D1099-D1106.

Sambrook, J.R., Russel, D., 2001. DW 2001. Molecular Cloning: A Laboratory Manual.

Schmidtova, J., Baldwin, S.A., 2011. Correlation of bacterial communities supported by different organic materials with sulfate reduction in metal-rich landfill leachate. Water Res. 45 (3), 1115-1128.

Shayan, S.I., Agblevor, F.A., Bertin, L., Sims, R.C., 2016. Hydraulic retention time effects on wastewater nutrient removal and bioproduct production via rotating algal biofilm reactor. Bioresour. Technol. 211, 527-533.

Sheoran, A., Bhandari, S., 2005. Treatment of mine water by a microbial mat: bench-scale experiments. Mine Water Environ. 24 (1), 38-42.

Sitte, J., Akob, D.M., Kaufmann, C., Finster, K., Banerjee, D., Burkhardt, E.-M., Kostka, J.E., Scheinost, A.C., Büchel, G., Küsel, K., 2010. Microbial links between sulfate reduction and metal retention in uranium-and heavy metal-contaminated soil. Appl. Envir. 76 (10), 3143-3152.
Velu, P., Peter, M.J., Sanniyasi, E., 2015. Effect of various carbon sources on biochemical production in marine microalgae Nannochloropsis salina (Eustigmatophyceae),

Dunaliella tertiolecta (Chlorophyceae) and Tetraselmis suecica (Chlorodendrophyceae). Int. J. Curr. Microbiol. App. Sci. 4 (3), 207-215.

Voříšková, J., Baldrian, P., 2013. Fungal community on decomposing leaf litter undergoes rapid successional changes. ISME J. 7 (3), 477.

Wei, L., Ma, F., Zhao, G., 2010. Composition and dynamics of sulfate-reducing bacteria during the waterflooding process in the oil field application. Bioresour. Technol. 101 (8), 2643-2650.

Xu, X., Chen, C., Wang, A., Guo, W., Zhou, X., Lee, D.-J., Ren, N., Chang, J.-S., 2014 Simultaneous removal of sulfide, nitrate and acetate under denitrifying sulfide removal condition: modeling and experimental validation. J. Hazard M. 264, 16-24.

Zhao, X., Kumarb, K., Gross, M.A., Kunetz, T.E., Wen, Z., 2018. Evaluation of revolving algae biofilm reactors for nutrients and metals removal from sludge thickening supernatant in a municipal wastewater treatment facility. Water Res (Under review). 